\title{
A new theory for membrane efficiency coefficient of compacted clay
}

\author{
Song Zhaoyang ${ }^{1}$, Wei Changfu ${ }^{2, a}$, and Zhao Chenggang ${ }^{1}$ \\ ${ }^{1}$ School of Civil Engineering, Beijing Jiaotong University, 100044 Beijing, China \\ ${ }^{2}$ State Key Laboratory of Geomechanics and Geotechnical Engineering, Institute of Rock and Soil Mechanics, Chinese Academy of \\ Sciences, 430071 Wuhan, China
}

\begin{abstract}
A new method for calculation the membrane efficiency coefficient $w$ of compacted clay is proposed in this paper. The influence of fixed negative charge on the surface of clay minerals is considered. What's more, the change of porosity during deformation is considered. Based on the chemical potential of specimens, the true ion concentration in pore-water is obtained. Based on the true ion concentration in pore water, the disjoining pressure considering fixed negative charge inside soils and the change of void ratio is proposed. A new calculation method for the membrane efficiency coefficient of compacted clay is established. The test data of $w$ considering different porosity are calculated and the calculated results are compared with the traditional calculation methods. The new calculation methods of $w$ provide a more physical-based theory for environmental geotechnical engineering.
\end{abstract}

\section{Introduction}

Membrane efficiency coefficient is the behaviour of porous medium to restrict the migration of solutes. Due to the semi-permeable membrane behaviour, compacted clay has been used as the engineering barriers in environmental geotechnical engineering (landfill, high-level nuclear waste disposal, et al.) to inhabit the migration of solutes harmful to humanity [1]. Therefore, the research of the membrane efficiency coefficient of compacted clays is essential for the safety of the environmental geotechnical engineering.

The membrane efficiency coefficient of compacted clay can be affected by many factors (such as the porosity, the concentrations of ions in pore-water, the mineral composition). [2,3] Extensive experimental research work on membrane behaviour of compacted clay has been carried out by researchers [4,5]. And experimental results have shown that the membrane behaviour of compacted clay would be enhanced with the decrease of the porosity $[6,7]$, the increase of the bentonite content [8], and the decrease of pore-fluid concentration [9-11].

Theoretical work on membrane properties of compacted clay has been carried out by researchers. The theoretical expression of membrane efficiency coefficient $w$ is $[12,13]$

$$
\omega=\frac{\Delta p}{\Delta \pi}
$$

Where $\Delta p$ is the measured pressure difference between the two boundaries of the tested specimen, $\Delta \pi$ is the theoretical pressure difference between the two boundaries of the tested specimen. However, until now, the van't Hoff equation has been used to calculate the theoretical pressure difference of the tested specimen by most researchers [14]. The expression of van't Hoff equation is

$$
\Delta \pi=v R T \Delta C
$$

Where $v$ is the quantity of ions per mole of the poresalt (i.e. for $\mathrm{KCl}, v=2$ ), $\mathrm{R}$ is universal gas constant ( 8.314 $\left.\mathrm{J} \mathrm{mol}^{-1} \mathrm{~K}^{-1}\right), T$ is Kelvin temperature $(\mathrm{K}), \Delta C$ is the concentration difference of pore-salt between the top and bottom boundaries of the tested sample. Two forms of pore-salt concentration difference are adopted by researchers: the first form is the concentration difference between the boundaries of tested sample in the initial state $\Delta C_{0}$ (the corresponding theoretical pressure difference and membrane efficiency coefficient are $\Delta \pi_{0}$ and $w_{0}$ ), the other form is the average concentration difference between the boundaries of tested sample in the average state $\Delta C_{\text {ave }}$ (i.e. the average ion-concentration of initial and steady state, and the corresponding theoretical pressure difference and membrane efficiency coefficient are $\Delta \pi_{\text {ave }}$ and $w_{\text {ave }}$ ).

As mentioned above, the tested results have shown the membrane characteristics of compacted clay are affected by many factors. However, the pore-fluid is ideal fluid is assumed in the van't Hoff equation, which was improved by Fritz et al. through the activity of the pore-water [14]. What's more, the true ion-concentration in pore-water and the effect of deformation are not considered by the above theoretical chemico-osmotic pressure difference.

A new calculation method of membrane efficiency coefficient $w$ is proposed in this paper. The true ionconcentration in pore-fluid and the effect of deformation are considered in the new theoretical chemico-osmotic pressure difference and membrane efficiency coefficient.

a Corresponding author: cfwei@whrsm.ac.cn. 


\section{The calculation of the membrane efficiency coefficient}

\subsection{The movable ions in pore-water}

As shown in Fig.1, fixed negative charge exists on the surface of the clay mineral due to the isomorphic substitutions and complexation reactions [15]. Part of the positively charged cations would be attracted near the surface of the clay mineral under the electric field of fixed negative charge. As a result, part of the positively charged cations cannot move with the flow of pore-fluid. Therefore, the actual pore-ion concentration is not the measured poreion concentration. The pore-fluid that contain the movable ions is defined as equilibrium solution.

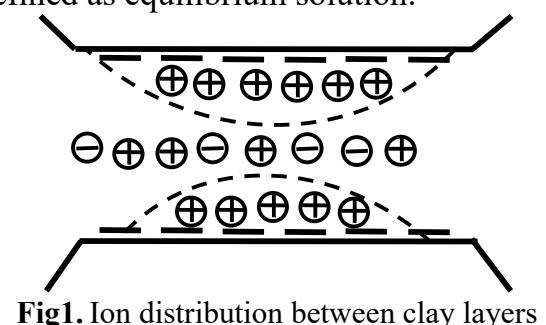

Based on the chemical potential of components in pore-fluid, the true ion concentration in pore-water of clay has been proposed by the authors [16-18]. $\mathrm{KCl}$ solution has been used as the pore-solution in membrane behaviour tests of compacted clay by researchers [4-9, 13]. Assuming that the pore solution is a $\mathrm{KCl}$ solution, the true concentration of pore ions is

$$
\begin{aligned}
& c^{K^{+}}=\frac{c_{f i x}}{2 n}\left(\sqrt{1+\left(\frac{2 n c}{c_{f i x}}\right)^{2}}+1\right) \\
& c^{C l^{-}}=\frac{c_{f i x}}{2 n}\left(\sqrt{1+\left(\frac{2 n c}{c_{f i x}}\right)^{2}}-1\right)
\end{aligned}
$$

Where $c^{\mathrm{K}+}$ and $c^{\mathrm{Cl}-}$ are the true concentration of $\mathrm{K}^{+}$and $\mathrm{Cl}^{-}$in pore-water, $n$ is the porosity of the compacted clay, $c$ is the measured pore-salt concentration, $c_{\text {fix }}$ is fixed charge density $\left(\mathrm{mol} / \mathrm{m}^{3}\right)$, which can be calculated by the following equation

$$
c_{f i x}=10 \times C E C \times \rho_{d}
$$

Where CEC is the exchangeable cation capacity $(\mathrm{mmol} / 100 \mathrm{~g}), \rho_{\mathrm{d}}$ is dry density of compacted clay $\left(\mathrm{g} / \mathrm{cm}^{3}\right)$, equals $(1-n) G_{\mathrm{s}}$, where $G_{\mathrm{s}}$ is the specific gravity of compacted clay.

\subsection{The theoretical chemico-osmotic pressure}

Based on the activity of pore-water, the theoretical chemico-osmotic pressure can be represented by

$$
\Pi_{\mathrm{D}}=\frac{\mathrm{R} T \rho^{l_{\mathrm{H}} \mathrm{O}}}{\mathrm{M}_{\mathrm{H}_{2} \mathrm{O}}} \ln \left(\frac{a_{\mathrm{ew}}}{a_{\mathrm{pw}}}\right)
$$

Where $\mathrm{M}_{\mathrm{H} 2 \mathrm{O}}$ is the molar mass of water $(18 \mathrm{~g} / \mathrm{mol}), a_{\mathrm{ew}}$ and $a_{\mathrm{pw}}$ are the activity of water $\left(\mathrm{H}_{2} \mathrm{O}\right)$ in equilibrium solution and pore-fluid of clay. $a=\gamma x$, where $x$ is the mole fraction of the specimen of water, $\gamma$ is nearly equals to 1 in dilute solution [19]. Taking account the true concentration of $\mathrm{K}^{+}$and $\mathrm{Cl}^{-}$in pore-fluid, the new theoretical chemicoosmotic pressure is

$$
\Pi_{\mathrm{D}}=R T\left[\frac{c_{f i x}}{n} \sqrt{1+\left(\frac{2 n c}{c_{f i x}}\right)^{2}}-2 c\right]
$$

The change of the proposed theoretical chemicoosmotic pressure difference with different factors (poresalt concentration, porosity and fixed charge density) are shown in Fig.2.

As shown in Fig.2, the influencing factors of membrane characteristics of compacted clay (the concentration of the pore-fluid, the porosity and the fixed charge density of the compacted clay) can all be considered in the new theory, which cannot be reflected in the van't Hoff equation.

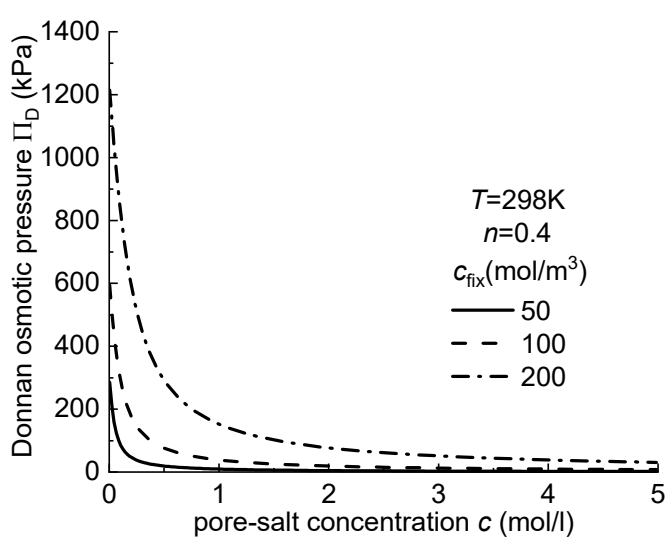

(a)

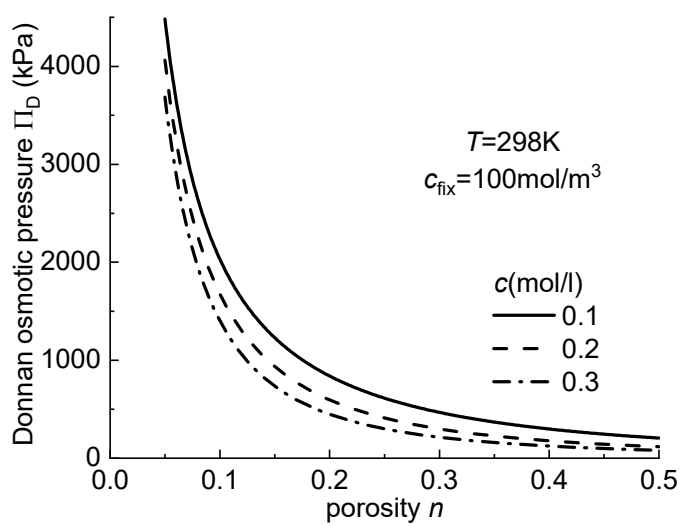

(b) 


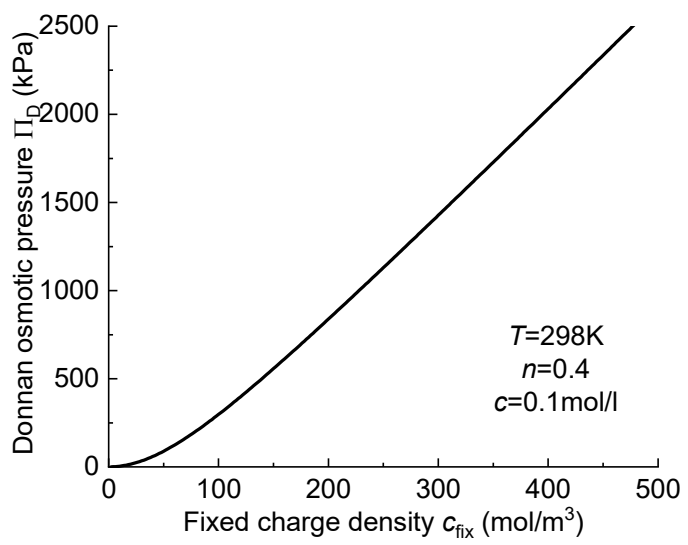

(c)

Fig2. The change of the proposed theoretical chemico-osmotic pressure difference with different factors

\subsection{The expression of the membrane efficiency coefficient}

Based on the proposed theoretical chemico-osmotic pressure difference, the expression of the membrane efficiency coefficient is

$$
\Delta \pi=\left(\Pi_{D}\right)_{\mathrm{b}}-\left(\Pi_{D}\right)_{\mathrm{t}}
$$

Then the membrane efficiency coefficient can be calculated by Eq.1.

\section{Case studies}

Membrane efficiency coefficient tests of compacted clay considering different porosity conditions was researched by Kang and Shackelford $(2009,2011)$ [6,7]. KCl solution was used as the pore-solution. The CEC and $G_{\mathrm{s}}$ of the compacted clay are $47.7 \mathrm{mmol} / 100 \mathrm{~g}$ and 2.43, respectively. The tested condition and the tested results are shown in table 1 (Where $n$ is the porosity of the tested soil, $C_{\mathrm{t} 0}$ is the initial concentration of $\mathrm{KCl}$ solution on the top boundary of the tested specimen while the bottom boundary with distilled water (i.e. $C_{\mathrm{b} 0}=0$ for all the tested specimen), $C_{\mathrm{t}}$ and $C_{\mathrm{b}}$ are the concentrations of $\mathrm{KCl}$ solution on the top and bottom boundaries of the specimen at the steady state of the test).

Table 1. Parameter table of the membrane efficiency coefficient tests

\begin{tabular}{|l|l|l|l|l|}
\hline$n$ & $\begin{array}{l}\Delta \mathrm{p} \\
(\mathrm{kPa})\end{array}$ & $\begin{array}{l}C_{\mathrm{t} 0} \\
(\mathrm{mmol} / \mathrm{l})\end{array}$ & $\begin{array}{l}C_{\mathrm{t}} \\
(\mathrm{mmol} / \mathrm{l})\end{array}$ & $\begin{array}{l}C_{\mathrm{b}} \\
(\mathrm{mmol} / \mathrm{l})\end{array}$ \\
\hline 0.8 & 8.117 & 3.9 & 2.68 & 0.63 \\
\hline 0.8 & 9.007 & 6 & 4.12 & 1.25 \\
\hline 0.79 & 8.572 & 8.7 & 5.81 & 2.19 \\
\hline 0.79 & 4.903 & 20 & 12.9 & 6.31 \\
\hline 0.79 & 2.29 & 47 & 30.3 & 15.2 \\
\hline 0.8 & 9.476 & 3.9 & 3.22 & 0.41 \\
\hline 0.8 & 10.966 & 6 & 4.84 & 1.12 \\
\hline 0.8 & 11.034 & 8.7 & 6.91 & 1.93 \\
\hline 0.8 & 11.028 & 20 & 14.7 & 5.25 \\
\hline 0.79 & 11.159 & 47 & 33.5 & 13.6 \\
\hline 0.77 & 12.062 & 3.9 & 3.25 & 0.441 \\
\hline
\end{tabular}

\begin{tabular}{|l|l|l|l|l|}
\hline 0.77 & 15.241 & 6 & 4.81 & 0.791 \\
\hline 0.76 & 16.552 & 8.7 & 6.87 & 1.43 \\
\hline 0.76 & 16.634 & 20 & 14.7 & 4.47 \\
\hline 0.76 & 16.131 & 47 & 33.2 & 12.7 \\
\hline 0.69 & 12.931 & 3.9 & 3.18 & 0.301 \\
\hline 0.68 & 15.952 & 6 & 5.05 & 0.711 \\
\hline 0.67 & 16.234 & 8.7 & 7.22 & 1.4 \\
\hline 0.66 & 17.593 & 20 & 15.5 & 4.23 \\
\hline 0.66 & 18.2 & 47 & 33.7 & 10.7 \\
\hline
\end{tabular}

The theoretical chemico-osmotic pressure difference of the tests are calculated with three methods (the calculation of van't Hoff equation with initial concentration difference and the average concentration difference between the top and the bottom boundaries of the specimen, the corresponding membrane efficiency coefficient are $w_{0}$ and $w_{\text {ave }}$, and the proposed method are calculated as well).

The calculated results of the proposed model are shown in Fig.3. The results show that the membrane efficiency coefficient increasing with the decreasing of the porosity and the concentrations of $\mathrm{KCl}$ solution, which are consistent with the previous research rules.

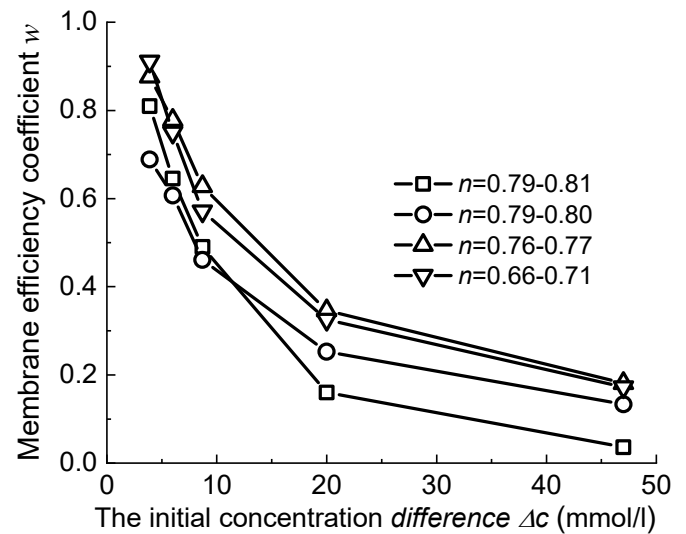

Fig3. The calculated membrane efficiency coefficient $w$ by the new theory

The comparison of the different calculation models are shown in Fig.4. The results show that the membrane efficiency coefficient of compacted clay calculated by the proposed theory are larger than the value calculated by traditional calculation methods. The analysis of the results is carried out below.

First of all, the initial concentration difference of $\mathrm{KCl}$ solution between boundaries of tested sample are larger than that in stable-state (part of the $\mathrm{KCl}$ component seeps through the sample), which means that the calculated chemico-osmotic pressure difference by van't Hoff equation using the initial ion-concentration difference is larger than the true values, then the calculated membrane efficiency coefficient $w_{0}$ is less than the true value.

The calculated membrane efficiency coefficient $w_{\text {ave }}$ is less than calculated value by the proposed model. However, $w_{\text {ave }}$ value is bigger than $w_{0}$. The reason is that the theoretical pressure difference $\Delta \pi_{\text {ave }}$ is closer to the true value compared with $\Delta \pi_{0}$ due to $\Delta C_{\text {ave }}$ is closer to the true ion-concentration difference compared with $\Delta C_{0}$, 
which means the calculated $w_{\text {ave }}$ value is bigger than $w_{0}$. However, the influence of deformation on the specimen is ignored by the calculation results $w_{\text {ave }}$ and $w_{0}$, which means that the $w_{\text {ave }}$ and $w_{0}$ are both smaller than the real value of membrane efficiency coefficient (tested results show that the membrane efficiency coefficient would increase with the decrease of porosity). The theory proposed by this paper is larger than the value of $w_{\text {ave }}$ and $w_{0}$ due to the consideration of the deformation of the tested sample.

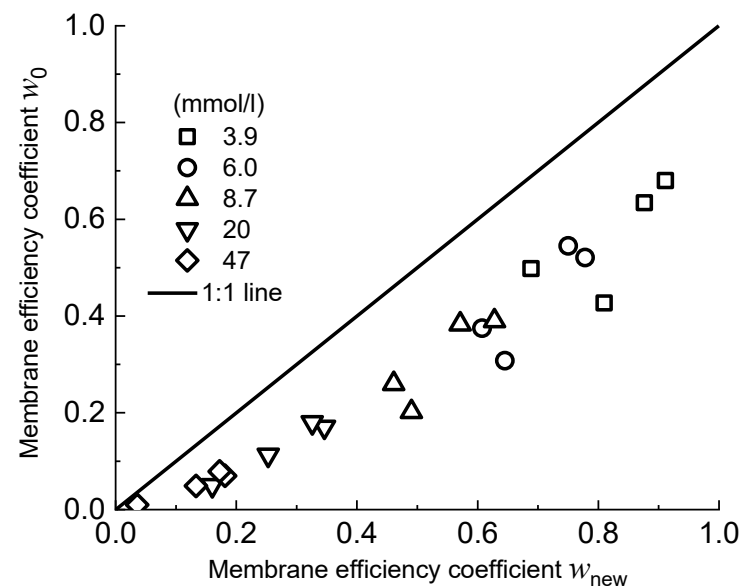

(a)

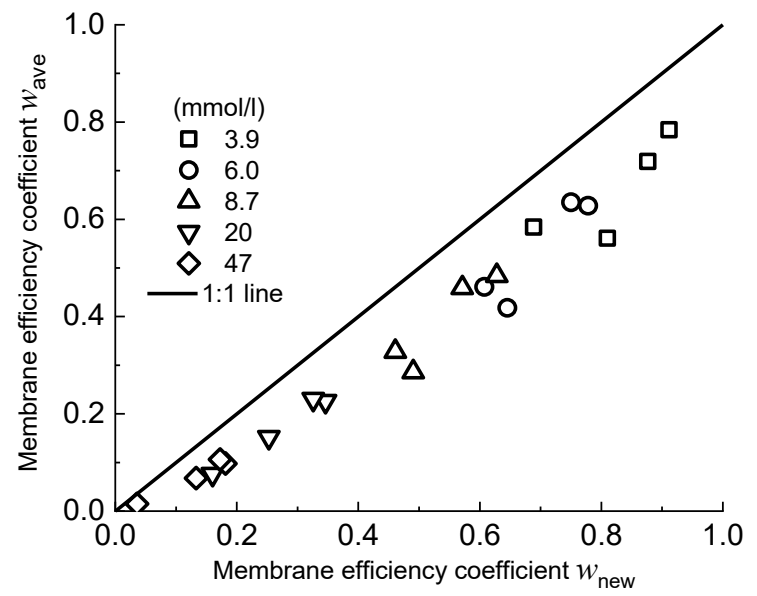

Fig4. The comparison of the calculated results

\section{Conclusion}

A new theory for calculation the membrane efficiency coefficient $w$ of compacted clay is researched in this paper. The true ion concentration of the pore-solution and the influence of deformation are considered in the proposed theory. The membrane efficiency coefficient of compacted clay is calculated and compared with the values calculated by van't Hoff equation. The calculation results show that the calculated membrane efficiency coefficient value by van't Hoff equation is conservative due to ignoring the effect of deformation of the tested sample.

\section{Acknowledgements}

The research was financially supported by the National Key R \& D Projects of China under Grant 2019YFC1509802, and Natural Science Foundation of China (NSFC) under Grant 51939011.

\section{References}

1. R.P. Chapuis Can. Geotech. J. 39 (2), 417-439 (2002)

2. W. D. Kemper, J. B. Rollins. Soil Sci. Soc. Am. Proc., 30(5), 529-534 (1966)

3. Mitchell, J. K. Fundamentals of soil behavior, 2nd Ed., Wiley, New York (1993)

4. S.S. Yeo, C.D. Shackelford, J.C. Evans. J. Geotech. Geoenviron. Eng. 131 (4), 418-429. (2005)

5. C. Fritz. M.S. thesis, Colorado State Univ., U.S. (2017)

6. J. Kang, and C. Shackelford. Appl. Clay Sci. 44 (12), 43-58 (2009)

7. J. Kang, and C. Shackelford. Geotext. Geomembr. 29 (6), 544-556 (2011)

8. Q, Tang, T. Katsumi, T. Inui, and Z. Li. Soils Found. 54 (3), 329-344 (2014)

9. M. Malusis, and C. Shackelford. J. Geotech. Geoenviron. Eng. 128 (2), 97-106 (2002)

10. M. A. Malusis, A. S. Daniyarov. Geotextiles and Geomembranes, 44(5) , 719-730 (2016).

11. A. Meier, C. Shackelford. Can. Geotech. J. 54 (9), 1284-1299 (2017)

12. P.H. Groenevelt, D.E. Elrick. Soil Sci. Soc. Am. J. 40(6), 820-823 (1976)

13. M. Malusis, C. Shackelford, H. Olsen. Geotech. Test. J. 24 (3), 229-242 (2001)

14. C. J. Fritz, J. Scalia IV, C. D. Shackelford, M. A. Malusis. J. Geotech. Geoenviron. Eng., 146(1), 06019018 (2020)

15. J. Gonçalvès, P. Rousseau Gueutin, G. de Marsily, P. Cosenza, S. Violette. Water Resour. Res., 46, W04514 (2010)

16. C. F. Wei. Vadose Zone J. 13(9), 1-21 (2014)

17. T. Ma, C. Wei, P. Chen, W. Li. Géotechnique. 69(4), 308-319 (2019)

18. Z. Y. Song, C. G. Zhao, C. F. Wei, T. T. Ma. Rock and Soil Mechanics, 41(8), 1-10 (2020)

19. I. Tinoco, K. Sauer, J.C.Wang. Physical Chemistry. Prentice-Hall, Upper Saddle River, N.J. (1995) 